\title{
The Importance of Sociolinguistics in Foreign Language Education: A Review of Selected Paper
}

\author{
Jimmy Saputra1,a, Muhammad Rahmadeny'1,b, Ichsan Jazzawi1,c \\ 'Department of English Language Education, Faculty of Teachers Training and Education, University of Lancang Kuning, Riau, 28265, Indonesia. \\ a jimmysaputra690@gmail.com; b m.rahmadeny29@gmail.com; c ichsanjazzawi@gmail.com \\ ${ }^{*}$ Corresponding Author \\ Whatsapp Number [+6285278037490]
}

How to Cite: Saputra, J., Rahmadeny, M.,\& Jazzawi, I. (2019). The Importance of Sociolinguistics in Foreign Language Education: A Review of Selected Paper. International Journal for Educational and Vocational Studies, 1(4), 299-303

\section{ARTICLE HISTORY}

Received: 12 May 2019

Revised: 16 June2019

Accepted: 5 August 2019

\section{KEYWORDS}

Sociolinguistic;

Foreign Language;

Context EFL;

\begin{abstract}
This article aims to provide a brief description and review of the research conducted by Yasemin Bayyurt entitled "Current Perspectives on Sociolinguistics and English Language Education" published in The Journal of Language Teaching and Learning, using descriptive qualitative analysis, and this paper tries to understand the importance of sociolinguistics in learning foreign languages from the perspective of the researcher. In this paper, the position and importance of sociolinguistics in foreign language education is the main topic in this article. This article is intended to provide a brief review of sociolinguistics and its importance in learning foreign languages. The findings in this study see that the research of Yasemin Bayyurt discusses and develops the definition of linguistic language and the relationship between sociolinguistics and foreign language education which will be explored in depth in 4 focuses. In it also mentioned the existence of several basic problems discussed in the sociolinguistic field, one example of which is variation and change language. The author examines this in three dimensions, namely the attitude towards foreign language learning, the inclusion of culture in foreign language learning, and the contribution of language planning to foreign language education. So with the findings in this study, hopefully it can be a reference for readers and hope that it can also be a replica in real life.
\end{abstract}

This is an open access article under the CC-BY-SA license.

\section{INTRODUCTION}

English is a language that is used as a medium of communication and as the first international media used to interact with other people throughout the world. English is not only important in communicating directly, but is also very important and influential in the world of education. This is because in the era of increasingly sophisticated technology, English is very much needed to be able to communicate digitally as well as through the internet, even the professional world also needs it. In addition, for students learning English is also important because it will help students to get the opportunity to study in the country of people who generally also use English as the main language in communication. By having the ability to speak English, it will certainly make it easier for students to interact in the land of people.

Based on this, we can imagine that English is like a bridge that can connect someone with someone, someone with a group, or a group with a group with one language to communicate. Therefore, English is important to know and learn. Cook, 1999 said that, "Broadly speaking, foreign - language teaching has two goals. The first, typically realized in the classroom, is that students learn the formal properties of a language and get some practice using it in communicative situations. The second goal, realized outside the classroom, is that students actually communicate with people in an L2 environment".

According to McKay (2003) in her theoretical approach, "emphasizes that English is a world language and that the local and international culture must be represented in the teaching of English". However, a controversial problem occurred, namely acceptance of the approach within the scope of the Kachru three-circle model. "Kachru (1985) classified world countries according to the status of English in each country as inner circle, outer circle and expanding

Foreign Language is "a language used by people to communicate between borders or with other people who are not from their country". Nunan (2005: 9) also mentions that "the ability to use a second language (knowing" how ") will be developed automatically if the learners are required to focus on communication. 
While according to Richard and Schmidt, foreign languages are "A language that is not the "Native Language" of large numbers of people in a particular country or region, is not used as a medium in instruction, and is not widely used as a medium of communication in government, media, etc. "Foreign language is usually taught as a language for reading printed materials in the language." From Richard and Schmidt's quote above, it can be concluded that foreign languages are interpreted as one language that is not the native language of most people in a particular country or region, nor is it used as a means of communication in government, media and so on. But foreign languages are taught as subjects in schools with the aim that students can communicate with strangers or to read reading in a foreign language and understand it."As Smith (1976) proposes, English as an international language does not belong to any nation, a position that challenges theorists and researchers (See also Jenkins, 2003, 2007; Rajagopalan, 2004; Widdowson, 1994, 2003)".

There are times when you also need to be able to understand the differences between British English and American English so that you don't get confused if you encounter these differences. Because between English and American have different accents, therefore, the importance of learning English in our lives is very useful as well as in the world of education. Chaer (2009: 37) suggests the term target language which is a language that is being studied and wants to be mastered. The form of the target language can be in the form of mother tongue (first language (B1), second language (B2), and foreign language (BA). The second language is certainly not the same as foreign languages. what he learned was Indonesian, and the foreign language he would study was English.

On the other hand, Nelson Mandela who was an anthiapartheid revolutionary and a South African politician who had served as president in South Africa from 1994 to 1999 . He also said about the importance of English, namely "If you talk to a man in a language he understands, that goes to his head. If you speak to his own language, that goes to his heart. "Which means that when someone knows a language that is understood by others, it is better to use a language that is understood by others so that what we say is more understandable and able establish better friendships. For example, one time there were students at a university in Indonesia who were gathering and had various languages; students from Bandung certainly have their own language, namely Sundanese, and students from Yogyakarta also have their own language, namely Javanese.

When they communicate, they will not use their local language, because it is better to use their mother tongue "Indonesian" so that friendship or friendship is more established. As with English, when you talk to someone from another country who has a different language, it is better to use English so that communication is better understood and established better. And it is not possible to use language in each country because not necessarily understand each other later. Therefore, it must be careful in understanding the easy way to learn English, self-taught English speaking methods, ways to learn English listening, and fun speaking learning methods to support the application of the importance of learning English as a foreign language in the world of education.

Oemar Hamalik also explained that "Education is a process in order to influence students to be able to adjust as well as possible to the environment and thus will cause changes in themselves that allow it to function strongly in people's lives". Well in this case if it is associated with the importance of foreign language education in education, especially English so that students can function strongly in the lives of people with the ability to speak English.

Foreign language education has become an important phenomenon in the present era. This is for personal or professional needs, there are people who study foreign languages to qualify for education abroad, there are also those who communicate with colleagues in international companies, or to prepare themselves to get better jobs. To understand this phenomenon, extensive knowledge of the process of language acquisition, second or foreign language education, sociolinguistics in this article the importance of sociolinguistics in foreign language education will be examined and become a very important thinssg to know.

Sociolinguistics is a branch of linguistics that specifically examines the use of language in society. Initially sociolinguistics was called the sociology of language (sociology of language) or language in society. According to Trudgill (1974), "Sociolinguistics is that part of linguistic which is concered with language as social and cultural phenomenon."

The sociolinguistic background of a child influences the use of children's language in their daily lives. The same is true for children's understanding of English in the classroom in their education. For example, a child from a high social class whose parents often use English to interact does not have problems in using English in his education compared to children from low social classes whose parents rarely or even never use English in interacting makes using English the biggest problem for the child, because the child has never or rarely heard the foreign language in his family environment. Because the family is the first learning for a child. This makes children feel difficult and unpleasant speaking English in class situations during the teaching-learning process. And by having a high economy, it will be more beneficial to support their children's education in English.

Therefore, it is important to note that teaching foreign languages in a broader sense will involve teaching successful communication through the use of correct registers or appropriate varieties. So in short, sociolinguistics can be defined as a science that investigates the purpose and function of language in society. In this case trying to explain how language differs from one context to another and how people in one context communicate with people in other contexts (eg, non-native speakers; native-non-native speakers, and so on). ) Scientists working 
in the field of sociolinguistics also conduct research on how language is used in diverse social contexts and the suitability of language used in certain contexts, this is taking into account factors such as etiquette, interpersonal relations, and regional dialects.

In this review-based article, the author extends the sociolinguistic definition and the relationship between sociolinguistics and foreign language education which will be explored in depth in 4 focus, namely what is sociolinguistic, what are its main components, in what ways sociolinguistics contributes to foreign language education and what is the relationship between sociolinguistics and teaching English as a foreign language.

\section{METHOD}

This article uses a qualitative approach to analyze the article entitled "Current Perspectives on Sociolinguistics and English Language Education" Written by Yasemin Bayyurt1 consisting of 10 pages and reinforced with 44 references in The Journal of Language Teaching and Learning, 2013-1,69-78.

In this review-based article, the author extends the sociolinguistic definition and the relationship between sociolinguistics and foreign language education which will be explored in depth in 4 focus, namely what is sociolinguistic, what are its main components, in what ways sociolinguistics contributes to foreign language education and what is the relationship between sociolinguistics and teaching English as a foreign language (p. 70). This article also tries to see the strengths and weaknesses of the article with the aim of giving ideas and input to academia. The contents in this article will also provide information on how important sociolinguistics is in the use of foreign languages in education. By looking at this article, hopefully it can be a reference for readers and hope that it can also be a replica in real life.

\section{RESULTS AND DISCUSSION}

\section{Strengthness}

Judging from the title, this article has the title "Current Perspectives on Sociolinguistics and English Language Education" ( $p, 69)$. This title is effective and can be understood by the reader even though it just reads the title. Research articles are also clear in their purpose rather than relying on the intelligence of fast readers. The title of this article has also been well synchronized by the abstract.

On the other hand, the abstract that the author put forward is also very good, because the author summarizes the contents in the article briefly, to the point, and with effective sentences that are not long-winded so the reader is interested in reading it and the points delivered in the abstract can immediately comprehensively understood by the reader ( $p, 69)$ Because the main point of a good abstract is when the reader can understand the entire contents of the article even if only by reading the abstract.

This article has many references, 44 references ( $p$,
77-78). Where this will be very useful and influential for the reader. With so many references in an article, the reader will be more confident with the articles he reads. This is also reinforced by footnotes written on each page which is located at the bottom, some containing the words $(p, 73)$, names of experts ( $p, 72)$, and also other information related to that page $(p, 71)$ and this is very effective because it helps the reader to understand the contents of the article. Not to forget also in every sense the name of the expert is also included (p, 72).

Besides having a lot of good references and abstracts, this article also uses a language that is easily understood by the reader, the sentence is also not complicated so that it becomes one of the attractions for the reader. Besides that, the author also does not forget to include the expert name in each statement $(p, 72)$, and this will also make the readers more confident about the statement.

\section{Weakness}

This review-based article entitled "Current Perspectives on Sociolinguistics and English Language Education" is quite good because it is equipped with footnotes below which make the reader very helpful in understanding the contents of the article (p, 71-75), but on the other hand, especially on the page First, the page number does not appear, this is of course trivial, but it should be overcome. Because wherever it is, the page number certainly starts from the first and next page.

On the other hand, in this article there is also no volume. At the top of the article on the first page also written "2013-1, 69-78" (p, 69) this is certainly a question for readers of what is meant by that number. What was meant by 2013-1. The author should be able to provide a more detailed explanation so that it does not become a question for the reader.

The article entitled "Current Perspectives on Sociolinguistics and English Language Education" written by Yasemin Bayyurt has a peculiarity in point number 2, namely the expanded definition of sociolinguistics page 71 which mentions the existence of several basic issues discussed in the field of sociolinguistics. in the article, including variations and changes in language variation and style, language attitude, language and culture, language and interaction, and so on. But the problem in this case is that the author only mentions the basic problem, but there is no further explanation and answers to the problem.

In this review-based article, the keyword is indeed available, it's just less synchronous with the content, because in the abstract alone, only a few keywords are found ( $p, 69)$. Especially in the content of the article, it is rare to find keywords that are keywords in it. This of course must be overcome, the use of keywords is to make it easier for the reader in his focus when reading an article, so automatically, the words contained in the keyword will often appear in the reading because the word is the focus in an article. But in this article, the appearance of words in keywords is very rare and almost nonexistent. Or some of 
the keywords created by the author contain implicit meanings so that they are rarely encountered, one example is Narrative storyline complexity. Well of course there are no such words found in the contents of the article, as well as others. It is better if you make keywords, it should be more effective so that readers are also more helped by the existence of these keywords.

Viewed from the content, this article is quite good and is useful as a reference for readers in the world of education about the importance of sociolinguistics in learning foreign languages, namely English. It's just that when seen from the points in it, it is a bit annoying because of the usual articles, in general the points are abstract, introduction, method, result, discussion, conclusion and references. Now in this article, the big points are only abstract, instroduction, discussion and conclusion, and references. Other points are such as The Expanded Definition of Sociolinguistics (page 70 point number 2), Language Attitude (Pages 71 point number 3), Language attitudes and foreign language education (Pages 72 points number 4), Language and Culture (Page 72 points number 5), The place and significance of foreign language education (Pages 73 points number 6), Foreign Language Planning and Policies (Page 73 points number 7), and the last is Teaching English and International Language (Page 75 point number 8).

This review-based article looks at the problems found in the article entitled "Current Perspectives on Sociolinguistics and English Language Education" written by Yasemin Bayyurt. This can be seen in the content of the article where there are no method and result parts like the usual article. While the author explores only a few focus points (p, 70-75).

\section{Discussion}

This review-based article entitled "Current Perspectives on Sociolinguistics and English Language Education" Written by Yasemin Bayyurt1 consisting of 10 pages and reinforced with 44 references in The Journal of Language Teaching and Learning, 2013-1,69-78 has developed a sociolinguistic subcomponent that such as language attitude, language and cultural relations in foreign language education, the place and importance of foreign language education, and language planning in foreign language education. In this vast world, to maintain good relations with other countries, the same language in communication is very important. To develop widespread foreign language skills, it is important to promote a positive attitude towards language that will be taught for example like English.

In this article, we find some strengths and weaknesses in it, of course we are not familiar anymore that something in this world is nothing perfect. It's the same thing as humans who have never escaped mistakes. So of course with the existence of strengths and weaknesses here, it is expected to provide input that will build this article to be even better in the future.

Teaching foreign languages is difficult, not an easy thing, not even possible if students have a negative attitude towards the foreign language. Both in terms of the nationality of the language teacher or the teaching context. This is evident if a student does not like the lesson or the teacher who teaches, then somehow the lesson will be difficult to accept, because it starts with a negative nature, as well as the opposite. On this basis, the authors investigated the attitudes that exist in students towards the target language and the development of the method. And in this case, cultural integration into English language teaching is very helpful for students to understand the concept of foreign languages, thus learning English will increase. This aims to eradicate the statement that teaching foreign languages is difficult.

\section{CONCLUSION}

It can be concluded from the findings of this study that sociolinguistics plays an important role in the learning of foreign languages. The foreign language referred to here is English. Where at this time, English has become a very important language especially when communicating with people of different countries. This review-based article is also very good as a reference when it is associated with other fields of sociolinguistics and is a good reference for readers, especially students or teachers because this article is related to the field of education.

\section{REFERENCES}

Bayyurt, Y. (2006). Non-native English language teachers" perspective on culture in English as a Foreign Language classrooms. Teacher Development, 10(2), 233-247.

Cook, V.J. (1999). Going beyond the native speaker in language teaching. TESOL Quarterly, 33(2), 185-209.

Hamalik, O. (2008). Education Teacher Competency Based Approach. Jakarta: Earth Literacy.

Jenkins, J. (2007). English as a lingua franca: Attitude and identity. Oxford University Press.

Kachru, B. B. (1985). Standards, codification and sociolinguistic realism: the English language in the outer circle. In R. Quirk \& H. Widdowson (Eds.), English in the World: Teaching and Learning the Language and Literatures (pp. 11-30). Cambridge: Cambridge University Press, 1985.

McKay, S. L. (2003). Teaching English as an international language. ELT Journal, 57(2), 139-148.

Nunan, D. (2005). From the special issues editor. Language Learning \& Technology, 9(3), 2-3.

Rajagopalan, K. (2004). 16 The Philosophy of Applied Linguistics. The handbook of applied linguistics, 397.

Richards, J. C., \& Schmidt, R. W. (2013). Longman dictionary of language teaching and applied linguistics. Routledge. 
Schmidt, R., Boraie, D., \& Kassabgy, O. (1996). Foreign language motivation: Internal structure and external connections. University of Hawai'i Working Papers in English as a Second Language 14 (2).

Smith, L. (1976). English as an international auxiliary language. RELC Journal, 7(2), 38-43.

Trudgill, P., \& Trudgill, S. (1974). The social differentiation of English in Norwich (Vol. 13). CUP Archive.

Widdowson, H. (2003). Defining issues in English language teaching. Oxford: Oxford University Press. 